\title{
Pemanfaatan Teknologi SMS Gateway dalam Implementasi Pemodelan Pelayanan Nasabah
}

\author{
Ari Suhartanto \\ Universitas Sebelas Maret Madiun \\ Madiun, Indonesia \\ E-mail: aritapiarikaja80@gmail.com
}

\begin{abstract}
Abstrak-Penelitian ini menggunakan metode Study Literatur yaitu dengan cara mengumpulkan informasi dari buku maupun internet yang berguna untuk pembelajaran dari sistem yang akan dibuat. Metodologi penelitian yang dijalankan menggunakan me tode kualitatif deskriptif. Sample data yang digunakan pada penelitian ini, menggunakan data nasabah PT. BPR Mandiri Dhanase jahte ra Madiun. Tahap-tahap dalam penelitian ini yaitu: mengumpulkan data, perencanaan sistem, pembuatan sistem, yang diteruskan dengan melakukan pengujian sistem jika semua sistem sudah selesai. Aplikasi yang digunakan dalam membangun sistem ini yaitu gammu, AppServ dan dreamweaver. Gammu adalah software yang digunakan untuk menghubungkan modem dengan komputer sehingga dapat digunakan untuk melakukan pengiriman sms atau mene rima sms. AppServ disini digunakan untuk menge lola database yang berguna untuk menyimpan semua data yang ada dalam sistem. Dalam penelitian ini menghasilkan satu sistem yang dapat membantu nasabah dan staff AO untuk mengirimkan pesan konfirmasi pembayaran angsuran dan denda kredit.
\end{abstract}

Kata Kunci-Sistem Pelayanan Nasabah, SMS Gateway

\section{Pendahuluan}

SMS (Short Message Service) merupakan salah satu mode komunikasi yang handal saat ini, SMS adalah layanan yang disediakan oleh ponsel operator untuk mengirim dan menerima pesan singkat. SMS dinilai sangat praktis, murah, dan efisien. Perilaku pengguna ponsel sampai saat ini dapat dikatakan bahwa setiap SMS yang masuk kemungkinan besar atau bahkan pasti akan dibaca karena sifat ponsel yang personal. Selain untuk mengirim pesan antar pengguna ponsel, SMS juga cocok untuk diterapkan dan berinteraksi dengan suatu sistem informasi berbasis komputer.

Bank perkreditan rakyat merupakan suatu bank yang kegiatannya meliputi simpanan dan pinjaman, dalam hal ini yang dimaksud adalah melayani simpanan dan pinjaman para nasabah dan juga karyawan pada bank tersebut itu senidiri. Bank perkreditan rakyat umumnya didirikan agar menjadi solusi dalam mengatasi permasalahan nasabahnya dalam hal bantuan pinjaman (modal berupa uang). 
Jurnal INTENSIF, Vol.1, No.1, Februari 2017

ISSN: $2549-6824$

Persoalan yang dihadapi oleh pihak bank perkreditan rakyat saat ini adalah sistem pelayanan nasabah masih secara manual dengan cara mengunjungi satu per satu nasabah sehingga terlalu banyak memakan waktu dan menghabiskan banyak biaya transportasi untuk para debtcollector dan Account Officer (AO). Oleh karena itu, dibutuhkan sebuah sistem informasi pelayanan untuk nasabah. Salah satunya, adalah dengan membuat sebuah aplikasi sistem informasi pelayanan nasabah berbasis SMS service dengan Gammu SMS Gateway

Tora Fahrudin (2011) dalam tugas akhirnya beranggapan, Didalam era informasi sekarang, penyampaian informasi kampus tidak selalu harus berupa spanduk ataupun brosur yang ditempatkan di tempat strategis di sekitar kampus. Sms merupakan suatu media yang di era sekarang sudah menjadi kebutuhan primer bagi mahasiswa. Melalui kultur inilah, penulis ingin memanfaatkan media tersebut sebagai sarana tambahan untuk menyebarkan informasi kepada mahasiswa.Pemberitahuan informasi berupa akademik atau non akademik bisa disebarkan melalui sms gateway yang bisa diakses oleh setiap unit. Penelitian ini akan memfokuskan model pembuatan sms gateway Politeknik Telkom baik untuk sms broadcast ataupun request. Hasil perancangan dari penelitian ini bisa dimanfaatkan untuk diimplementasikan lebih lanjut. pengiriman sms broadcast diintegrasikan dengan menu approval keuangan, menu perwalian. Ketika mahasiswa sudah diproses keuangannya, maka sistem akan mengirim sms broadcast kepada mahasiswa yang sudah diproses oleh bagian keuangan secara otomatis. Begitu juga ketika perwalian, jika mahasiswa sudah melakukan input matakuliah dan mengklik siap acc wali, maka secara otomatis sistem akan mengirim sms broadcast kepada wali yang bersangkutan, begitu juga ketika wali sudah meng-acc matakuliah yang telah diinputkan, maka sistem akan membroadcast sms secara otomatis kepada mahasiswa yang bersangkutan, menginformasikan bahwa proses perwalian sudah selesai.

Sukamto (2011) dalam proyek tugas akhirnya beranggapan bahwa Pada era kecanggihan teknologi informasi sepeti sekarang ini. Komputer merupakan salah satu media komunikasi yang memiliki peranan sangat penting di dalam kehidupan sehari-hari baik oleh instansi organisasi ataupun pribadi. Beberapa teknologi informasi yang menyongsong pasar bebas memegang peranan sangat penting sehingga memerlukan sumber daya manusia yang berkualitas. Sumber daya manusia dengan mengikuti perkembangan jaman bias berperan penting dalam merubah kecanggihan suatu teknologi. Perubahan dan pembaharuan yang telah dicapai dalam bidang teknologi informasi seperti otomatisasi dan komputerisasi telah berkembang dengan cepat dan menuntut kalangan industri dan praktisi yang berkecimpung di dalamnya untuk lebih siap menghadapi kemajuan yang ada, dengan selalu mencari inovasi - inovasi baru sebagai solusi pemecahan dari setiap persoalan yang dihadapi. 
Jurnal INTENSIF, Vol.1, No.1, Februari 2017

ISSN: $2549-6824$

\section{Metode Penelitian}

Sistem SMS Gateway pada sistem informasi pelayanan nasabah PT. BPR Mandiri Dhanasejahtera Madiun merupakan sebuah sistem yang dibuat untuk membantu pengurus dalam mengelola koperasi. Sistem ini terbagi dalam dua macam pengguna, yaitu admin dan user umum. Admin memiliki hak akses untuk menambahkan, mengubah dan menghapus data sedangkan untuk user umum hanya dapat melihat informasi jumlah saldo tabungan dan jumlah pinjaman yang telah dilakukan. Metodologi yang digunakan dalam penelitian ini menggunakan metode System Development Life Cycle (SDLC), yaitu metode yang menggunakan pendekatan csecara sistematis dan urut mulai dari melakukan analisa kebutuhan, pengumpulan data, perancangan dan pembuatan, pengujian sistem sampai implementasi sistem terhadap tempat penelitian.



GAMBAR I. FLOWCHART ALUR PENELITIAN 


\section{Hasil \& Pemibahasan}

\section{A. Analisa Kebutuhan Sistem}

Spesifikasi tingkat kebutuhan sistem insformasi pelayanan nasabah BPR Mandiri Dhanasejahtera Madiun berbasis SMS service ini adalah sebagai berikut :

1. Sistem ini dapat digunakan untuk memasukkan dan mengedit data nasabah berdasarkan nama, alamat, no telepon dan pekerjaan yang telah memenuhi syarat untuk pengajuan kredit.

2. Sistem ini merupakan unit yang digunakan untuk mengatur aktifitas menu program untuk memanggil sub form atau sub modul pengelolaan informasi tagihan angsuran dan denda kepada nasabah.

3. Mengendalikan aktifitas program untuk penginputan data nasabah dan pembayaran atau angsuran serta laporan keseluruhan dari seluruh aktifitas program.

B. Perancangan Sistem

1. Flowchart Sistem

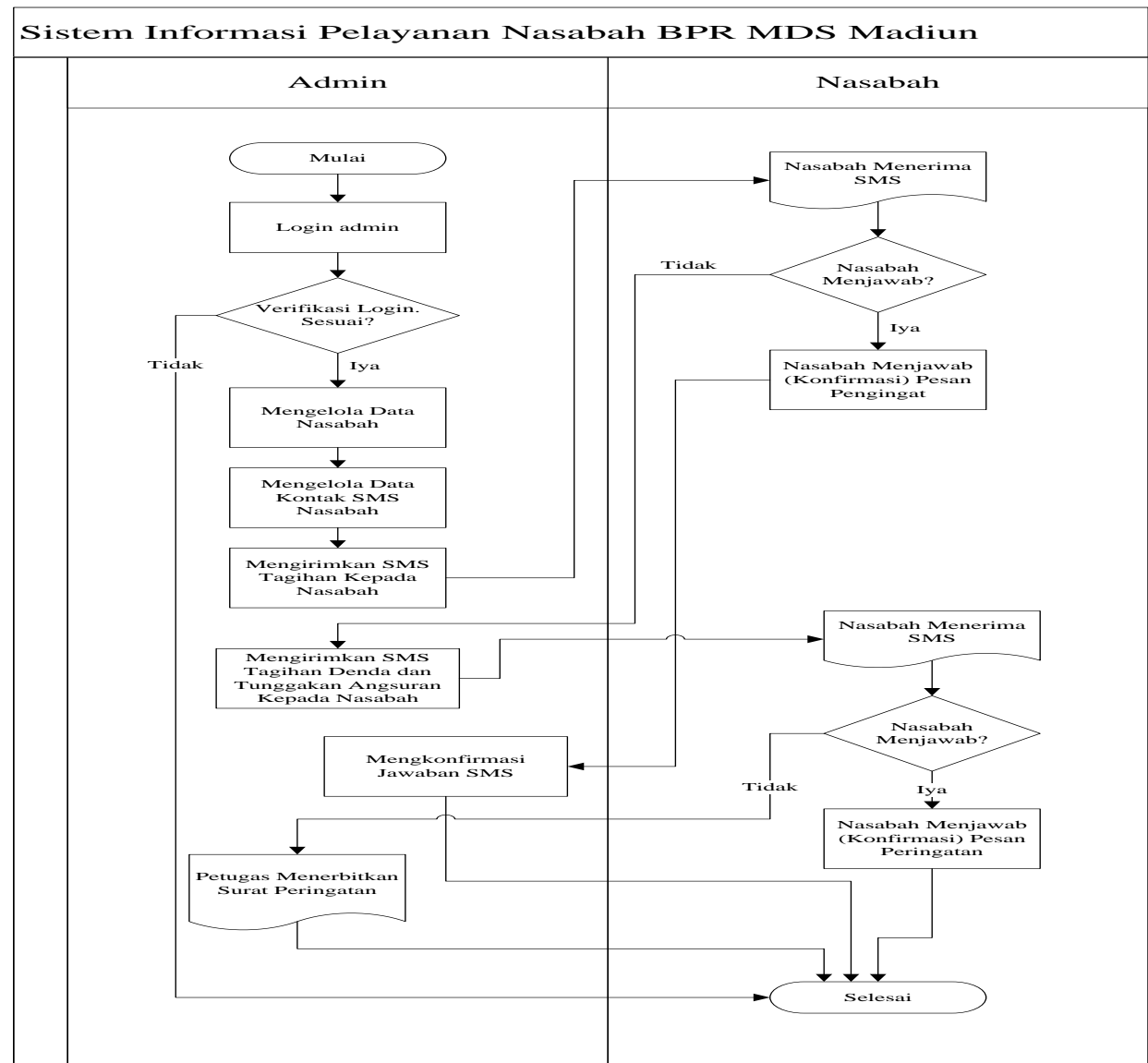

GAMBAR II. FLOWCHART SISTEM 
Jurnal INTENSIF, Vol.1, No.1, Februari 2017

ISSN: 2549-6824

\section{DFD Sistem}

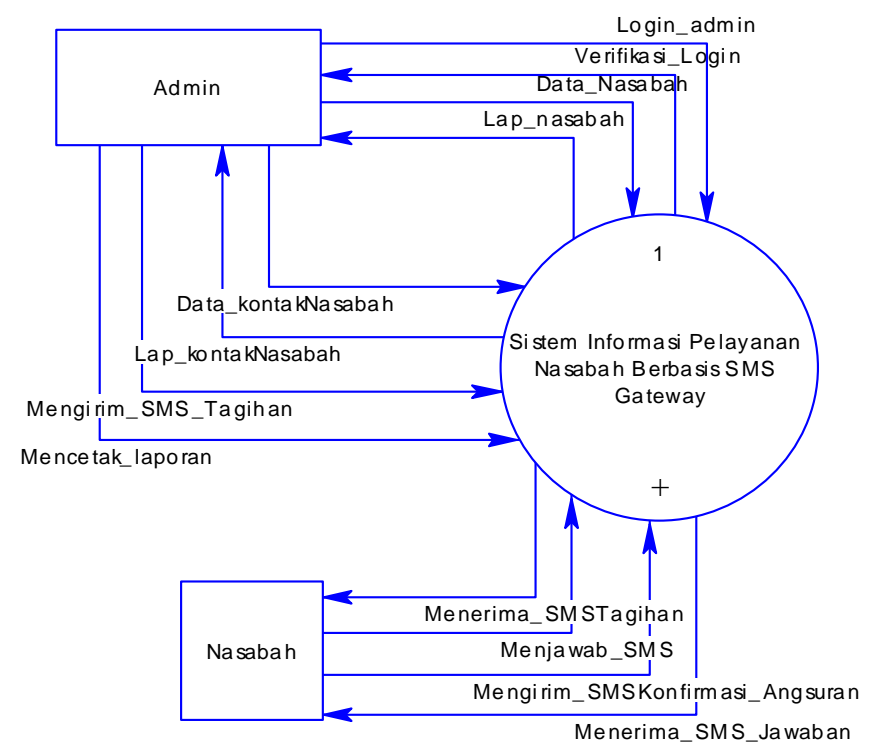

GAMBAR III. DFD LEVEL 0

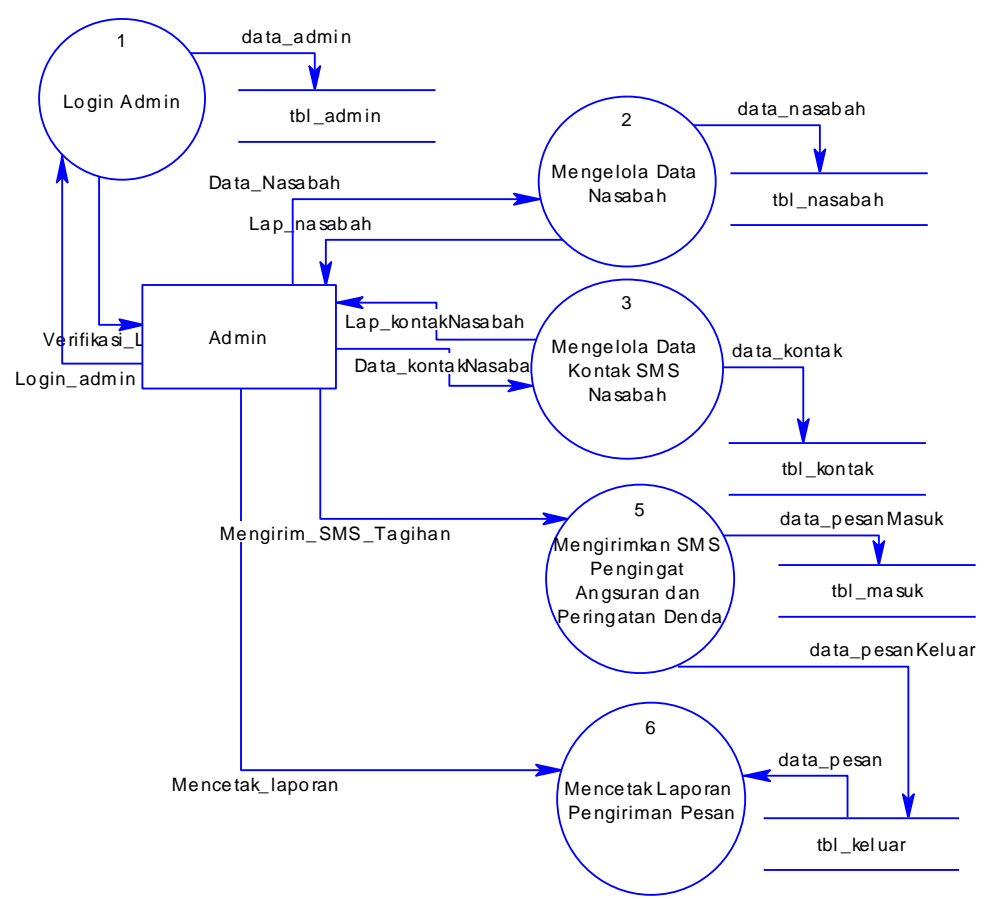

GAMBAR IV. DFD LEVEL 1 ADMIN 
Jurnal INTENSIF, Vol.1, No.1, Februari 2017

ISSN: $2549-6824$

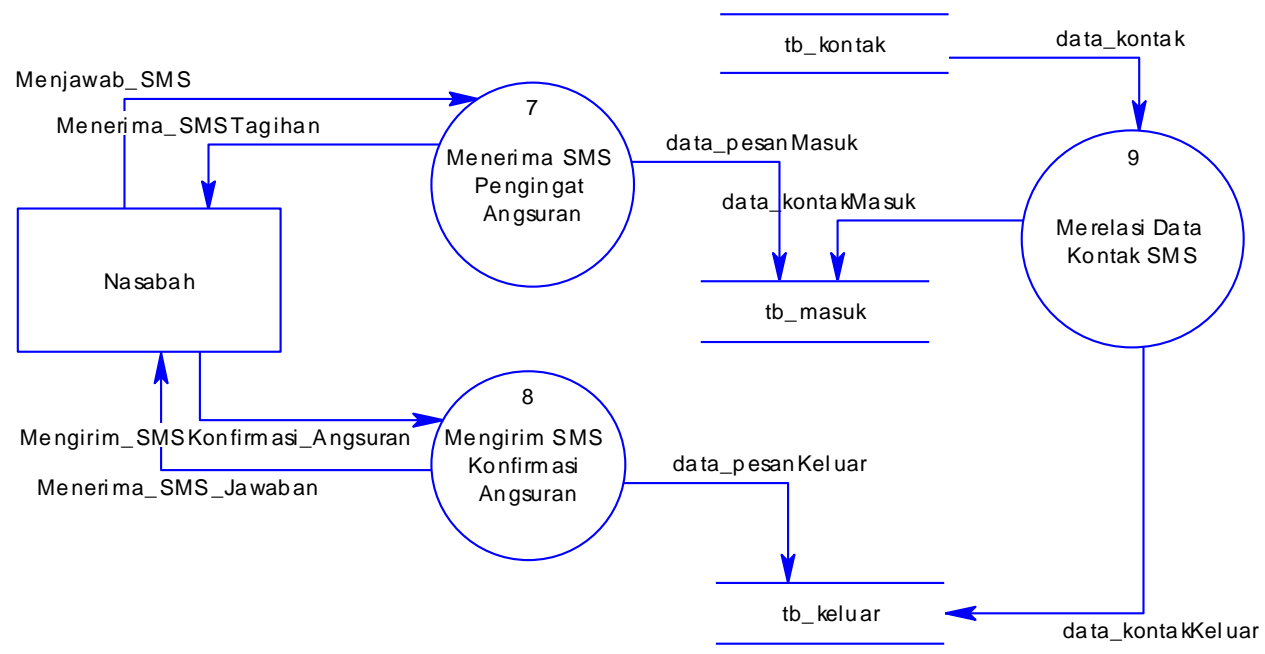

GAMBAR V. DFD LEVEL 1 NASABAH

\section{ERD Sistem}

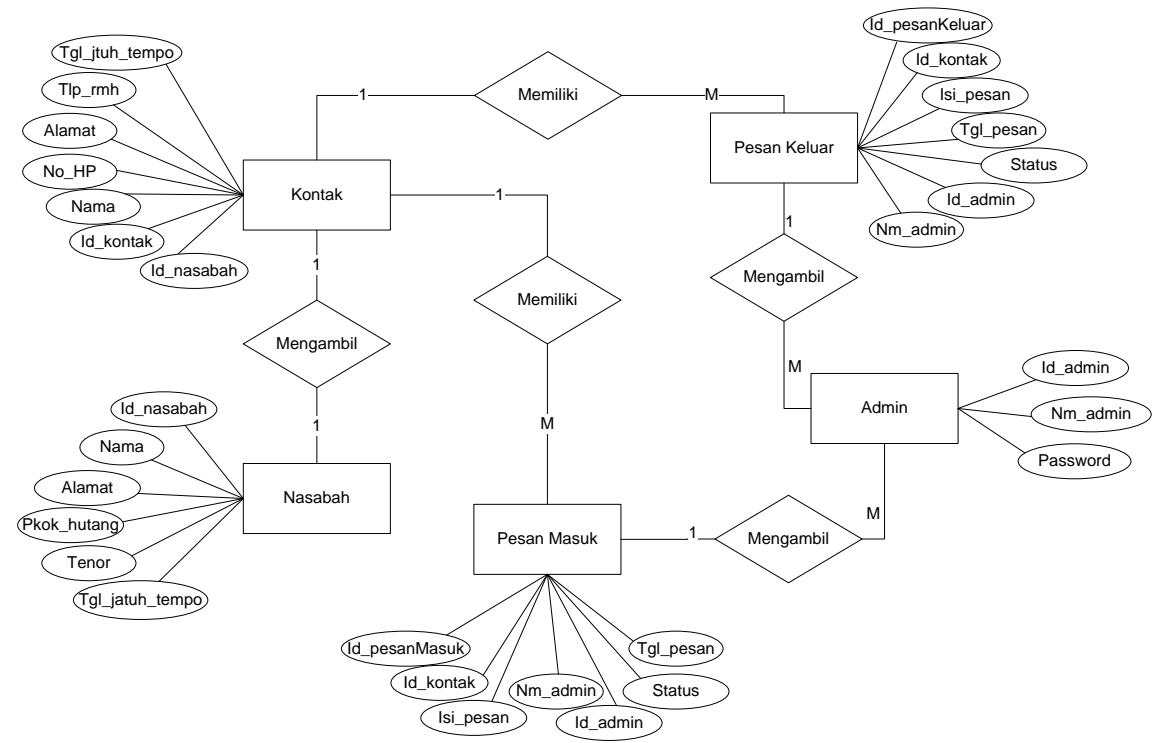

GAMBAR VI. ERD SISTEM

\section{Implementasi Sistem}

Hasil pembuatan sistem informasi pelayanan nasabah pada PT. BPR Mandiri Dhanasejahtera Madiun dapat dilihat pada deret tampilan gambar berikut: 
Jurnal INTENSIF, Vol.1, No.1, Februari 2017

ISSN: 2549-6824

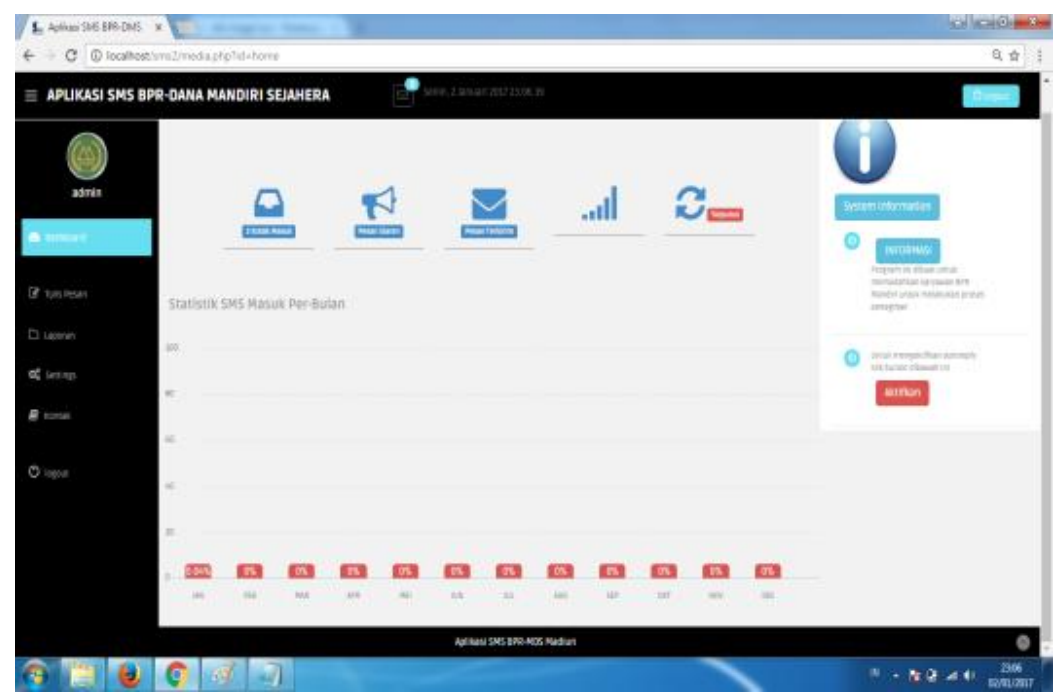

GAMBAR VII. HALAM AN DASHBOARD SISTEM

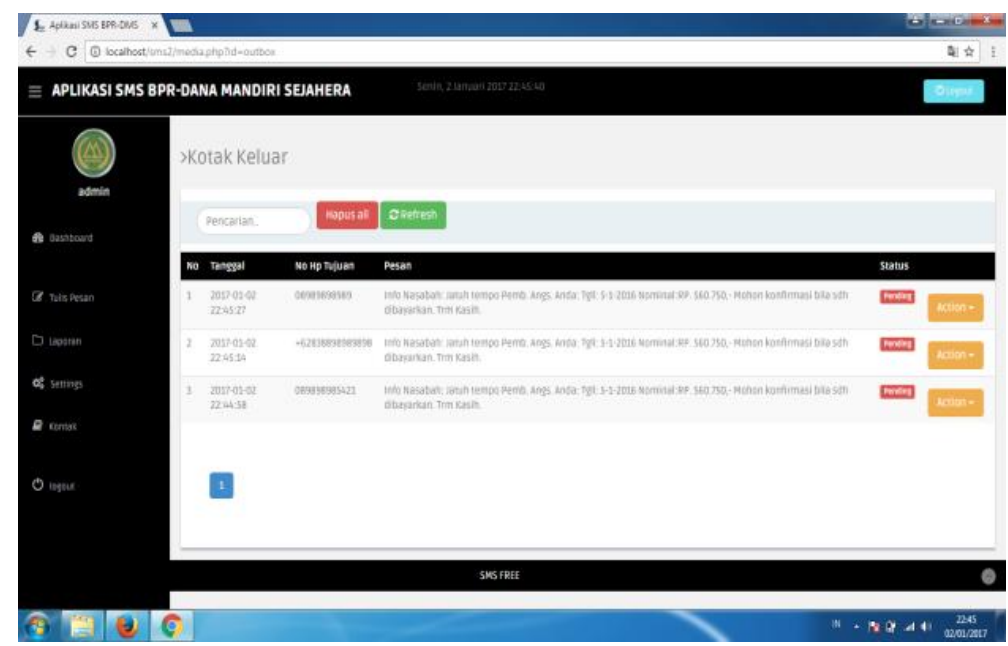

GAMBAR VIII. LAPORAN PESAN SMS

D. Hasil Uji Coba Sistem

1. Halaman Login Admin

TABEL I. HASIL UJI COBA FORM LOGIN

\begin{tabular}{|c|c|c|c|c|}
\hline No. & Tujuan & Input & $\begin{array}{l}\text { Hasil yang } \\
\text { diharapkan }\end{array}$ & Output Sistem \\
\hline 1 & $\begin{array}{l}\text { Menguji data } \\
\text { admin }\end{array}$ & $\begin{array}{l}\text { Memasukkan data } \\
\text { admin yang benar. }\end{array}$ & $\begin{array}{l}\text { Verifikasi data admin } \\
\text { berhasil }\end{array}$ & $\begin{array}{l}\text { Konfirmasi login } \\
\text { berhasil dan } \\
\text { menampilkan halaman } \\
\text { menu pengelolaan } \\
\text { sistem }\end{array}$ \\
\hline 2 & $\begin{array}{l}\text { Menguji } \\
\text { verifikasi data }\end{array}$ & $\begin{array}{l}\text { Memasukkan data } \\
\text { admin yang salah }\end{array}$ & $\begin{array}{l}\text { Menampilkan } \\
\text { kesalahan Login }\end{array}$ & $\begin{array}{l}\text { Menampilkan pesan } \\
\text { peringatan kesalahan } \\
\text { login }\end{array}$ \\
\hline & Kesimpulan & \multicolumn{3}{|c|}{$\begin{array}{l}\text { Proses verifikasi Login berhasil dan dapat memfilter hak akses pengguna } \\
\text { hanya pada level admin. }\end{array}$} \\
\hline
\end{tabular}


Jurnal INTENSIF, Vol.1, No.1, Februari 2017

ISSN: 2549-6824

2. Halaman Dashboard Sistem

TABEL II. HASIL UJI MENU DASHBOARD SISTEM

\begin{tabular}{|c|c|c|c|c|}
\hline No. & Tujuan & Input & $\begin{array}{l}\text { Hasil yang } \\
\text { diharapkan }\end{array}$ & Output Sistem \\
\hline 1 & $\begin{array}{l}\text { Proses Menu Ikon } \\
\text { dalam Dashboard }\end{array}$ & $\begin{array}{l}\text { Select menu } \\
\text { dashboard }\end{array}$ & $\begin{array}{l}\text { Menampilkan deret } \\
\text { ikon data yang dikelola } \\
\text { dalam sistem }\end{array}$ & $\begin{array}{l}\text { Ikon dapat } \\
\text { menampilkan kutipan } \\
\text { data yang dikelola } \\
\text { dalam sistem dan } \\
\text { menampilkan grafik } \\
\text { data. }\end{array}$ \\
\hline & Kesimpulan & \multicolumn{3}{|c|}{ Proses tampilan dashboard berjalan dengan baik. } \\
\hline
\end{tabular}

3. Halaman Form Mengirim Pesan (SMS)

TABEL III. HASIl UJi COBA FORM KIRIM PESAN

\begin{tabular}{|c|c|c|c|c|}
\hline No. & Tujuan & Input & $\begin{array}{l}\text { Hasil yang } \\
\text { diharapkan }\end{array}$ & Output Sistem \\
\hline 1 & $\begin{array}{l}\text { Menguji proses } \\
\text { mengirim pesan } \\
\text { secara manual. }\end{array}$ & $\begin{array}{l}\text { Memasukkan data } \\
\text { pesan yang benar. }\end{array}$ & $\begin{array}{l}\text { Pengiriman pesan } \\
\text { SMS berhasil }\end{array}$ & $\begin{array}{l}\text { Konfirmasi } \\
\text { pengiriman pesan } \\
\text { berhasil dan } \\
\text { menampilkan data } \\
\text { pesan terkirim pada } \\
\text { laporan pesan } \\
\text { terkirim. }\end{array}$ \\
\hline 2 & $\begin{array}{l}\text { Menguji kesalahan } \\
\text { kelengkapan data } \\
\text { input }\end{array}$ & $\begin{array}{l}\text { Textfield nomor } \\
\text { handphone tidak di } \\
\text { isi }\end{array}$ & $\begin{array}{l}\text { Menampilkan } \\
\text { kesalahan input }\end{array}$ & $\begin{array}{l}\text { Menampilkan pesan } \\
\text { peringatan kesalahan } \\
\text { kelengkapan input } \\
\text { data }\end{array}$ \\
\hline & Kesimpulan & \multicolumn{3}{|c|}{ Proses dan tata cara pengiriman dapat berjalan dengan baik. } \\
\hline
\end{tabular}

4. Halaman Pengelolaan Data Kontak

TABEL IV. HASIL UJi COBA FORM INPUT DATA KONTAK NASABAH

\begin{tabular}{lllll}
\hline \multicolumn{1}{c}{ Tujuan } & \multicolumn{1}{c}{ Input } & \multicolumn{1}{c}{$\begin{array}{c}\text { Hasil yang } \\
\text { diharapkan }\end{array}$} & Output Sistem \\
\hline 1 & $\begin{array}{l}\text { Menguji proses } \\
\text { input data kontak. }\end{array}$ & $\begin{array}{l}\text { Memasukkan data } \\
\text { kontak yang lengkap } \\
\text { dan benar. }\end{array}$ & $\begin{array}{l}\text { Proses input berjalan } \\
\text { dengan baik }\end{array}$ & $\begin{array}{l}\text { Konfirmasi proses } \\
\text { input berhasil. }\end{array}$ \\
& $\begin{array}{l}\text { Menguji kesalahan } \\
\text { kelengkapan data } \\
\text { input }\end{array}$ & $\begin{array}{l}\text { Textfield nomor } \\
\text { handphone tidak di } \\
\text { isi }\end{array}$ & $\begin{array}{l}\text { Menampilkan } \\
\text { kesalahan input }\end{array}$ & $\begin{array}{l}\text { Menampilkan pesan } \\
\text { peringatan kesalahan } \\
\text { kelengkapan input } \\
\text { data }\end{array}$ \\
& & Proses dan tata cara input data dapat berjalan dengan baik.
\end{tabular}


Jurnal INTENSIF, Vol.1, No.1, Februari 2017

ISSN: 2549-6824

5. Halaman Laporan

a). Laporan Data Pesan Masuk

TAB EL V. HASIL UJi COBA LAPORAN PESAN MASUK

\begin{tabular}{|c|c|c|c|c|}
\hline No. & Tujuan & Input & $\begin{array}{l}\text { Hasil yang } \\
\text { diharapkan }\end{array}$ & Output Sistem \\
\hline 1 & $\begin{array}{l}\text { Menguji proses } \\
\text { menampilkan data } \\
\text { pesan masuk. }\end{array}$ & $\begin{array}{l}\text { Select menu } \\
\text { laporan pesan } \\
\text { masuk }\end{array}$ & $\begin{array}{l}\text { Tertampil laporan } \\
\text { data pesan masuk }\end{array}$ & $\begin{array}{l}\text { Tertampil } \\
\text { laporan data } \\
\text { pesan masuk }\end{array}$ \\
\hline 2 & $\begin{array}{l}\text { Menguji menu export } \\
\text { data dalam format } \\
\text { cetak }\end{array}$ & $\begin{array}{l}\text { Select menu } \\
\text { export data }\end{array}$ & $\begin{array}{l}\text { Tertampil berkas } \\
\text { export data }\end{array}$ & $\begin{array}{l}\text { Tertampil berkas } \\
\text { export data cetak } \\
\text { laporan pesan }\end{array}$ \\
\hline & Kesimpulan & \multicolumn{3}{|c|}{ Proses menu laporan pesan masuk berjalan dengan baik. } \\
\hline
\end{tabular}

b). Laporan Data Pesan Keluar

TABEL VI. TABEL 6: Hasil Uл Coba Laporan PESAn Keluar

\begin{tabular}{cllll}
\hline \hline No. & \multicolumn{1}{c}{ Tujuan } & \multicolumn{1}{c}{ Input } & \multicolumn{1}{c}{$\begin{array}{c}\text { Hasil yang } \\
\text { diharapkan }\end{array}$} & Output Sistem \\
\hline \multirow{2}{*}{1} & $\begin{array}{l}\text { Menguji proses } \\
\text { menampilkan data pesan } \\
\text { keluar. }\end{array}$ & $\begin{array}{l}\text { Select menu } \\
\text { laporan pesan } \\
\text { keluar }\end{array}$ & $\begin{array}{l}\text { Tertampil laporan data } \\
\text { pesan keluar }\end{array}$ & $\begin{array}{l}\text { Tertampil } \\
\text { laporan data } \\
\text { pesan keluar } \\
\text { Tertampil }\end{array}$ \\
& $\begin{array}{l}\text { Menguji menu export } \\
\text { data dalam format cetak }\end{array}$ & $\begin{array}{l}\text { Select menu } \\
\text { export data }\end{array}$ & $\begin{array}{l}\text { Tertampil berkas } \\
\text { export data }\end{array}$ & $\begin{array}{l}\text { berkas export } \\
\text { data cetak } \\
\text { laporan pesan }\end{array}$ \\
& Kesimpulan & Proses menu laporan pesan keluar berjalan dengan baik. \\
\hline
\end{tabular}

c). Laporan Data Pesan Terkirim

TAB EL VII. TABEL 7: Hasil Ui Coba Laporan Pesan Masuk

\begin{tabular}{|c|c|c|c|c|}
\hline No. & Tujuan & Input & Hasil yang diharapkan & Output Sistem \\
\hline 1 & $\begin{array}{c}\text { Menguji proses } \\
\text { menampilkan data pesan } \\
\text { terkirim. }\end{array}$ & $\begin{array}{l}\text { Select menu } \\
\text { laporan pesan } \\
\text { terkirim }\end{array}$ & $\begin{array}{l}\text { Tertampil laporan data } \\
\text { pesan terkirim }\end{array}$ & $\begin{array}{c}\text { Tertampil } \\
\text { laporan data } \\
\text { pesan terkirim }\end{array}$ \\
\hline 2 & $\begin{array}{l}\text { Menguji menu export data } \\
\text { dalam format cetak }\end{array}$ & $\begin{array}{l}\text { Select menu } \\
\text { export data }\end{array}$ & $\begin{array}{c}\text { Tertampil berkas export } \\
\text { data }\end{array}$ & $\begin{array}{l}\text { Tertampil berkas } \\
\text { export data cetak } \\
\text { laporan pesan }\end{array}$ \\
\hline & Kesimpulan & \multicolumn{3}{|c|}{ Proses menu laporan pesan terkirim berjalan dengan baik. } \\
\hline
\end{tabular}

\section{KeSIMPULAN \& SARAN}

Setelah melakukan penelitian dan melalui hasil pengujian yang telah dilakukan dapat ditarik kesimpulan (1) Adanya sistem ini sangat membantu kinerja dari koperasi yang menyatakan lebih efisien dalam menggunakan sistem ini dikarenakan proses pengirimkan pesan SMS kepada nasabah tidak perlu dijalankan oleh setiap staff AO atau mengunjungi secara langsung, namun cukup dengan mengirimkan pesan pengingat angsuran dan jatuh tempo angsuran serta peringatan denda pembayaran karena keterlambatan. (2) Sistem telah diuji dan menghasilkan proses yang berjalan lancar sehingga 
sistem dapat diterapkan secara langsung pada instansi PT. BPR Mandiri Dhanasejahtera Madiun. (3) Dengan sistem berbasis SMS Gateway maka informasi yang disampaikan menjadi lebih real time sehingga tidak ada lagi alasan belum mendapat informasi. (4) Dengan sistem berbasis SMS Gateway maka semua informasi tersimpan dalam database, sehingga mudah dilacak, jika waktu kemudian untuk di butuhkan.

Sebagai saran pengembangan sistem yang dapat dijalankan (1) Sistem pelayanan nasabah berbasis SMS gateway ini sebaiknya dapat lebih dioptimalkan, sehingga tidak hanya terbatas pada pencatatan pelayanan tagihan saja tetapi dapat diperluas lagi, misalnya untuk mendukung informasi estimasi perhitungan angsuran dengan kriteria pokok hutang, angsuran dan analisis data keuangan nasabah. (2) Diperlukan pelatihan bagi staff pengguna sistem agar dapat mengoperasikan sistem ini dengan baik dan lancar. (3) Melakukan back-up data secara berkala untuk meminimalisasikan kemungkinan hilangnya data dari kesalahan-kesalahan yang tidak diharapkan. (4) Melakukan pemeliharaan secara berkala untuk perangkat lunak (software) dan perangkat keras (hardware).

\section{Daftar Pustaka}

[1] Al Fatta, Hanif. 2007. Analisis Dan Perancangan sistem Informasi. Yogyakarta : CV Andi Offset.

[2] Fahrudin, Tora. 2011. Pembuatan Model Sms Gateway untuk penyeberan dan Pengolahan Request Informasi civia akademik Politeknik Telkom. Teknik Komputer Politeknik Telkom, Bandung

[3] Gandhi, 2011. Tutorial Lengkap Membangun SMS Gateway Dengan Gammu Dan MySQL. http://www.ilmuprogrammer.com/2013/05/tutorial-sms-gateway-auto-reply-sms.html. Di akses pada tanggal 20 Agustus 2016 jam 12.13 WIB

[4] Kristanto, Hengki. 2012. Cara Cepat Membuat Website. Yogyakarta; Penerbit Andi.

[5] Maulani, Galih Prastiwi. 2012. Sistem Informasi Komputerisasi Koperasi Dengan Fitur Tambahan Sms Gateway Pada Kospin “Asli” Klaten. Sekolah Tinggi Manajemen Informatika dan Komputer, Yogyakarta

[6] Rahayu, Iis Tri. 2011 . Aplikasi Pemesanan Online Berbasis Sms Gateway (Studi Kasus Di Resto De’ Kasteel. Universitas Pembangunan Nasional“Veteran” Jawa Timur.

[7] Saputro, Yanuar Ary. 2011. Perancangan Sistem SMS Gateway berbasis Web dengan Gammu dan Interkoneksi di Biro Sistem Informasi Unissula Semarang, Universitas Diponegoro.

[8] Sukamto. 2011 . Aplikasi Pengelolaan Laundry berbasis Web Dan SMS Gateway sebagai sarana pemberitahuan. Universitas Pembangunan Nasional“Veteran” Jawa Timur.

[9] Tuwarno, Ramadhian Agus Triono. 2012. Sistem Informasi Simpan Pinjam Koperasi Mitra Mandiri Jetak. 